Témoigner Témoigner. Entre histoire et mémoire

Getuigen Revue pluridisciplinaire de la Fondation Auschwitz

$124 \mid 2017$

La musique dans les camps

\title{
Consuming the Holocaust
}

Over Sergei Loznitsa's Austerlitz: een subtiel manifest voor

een hernieuwd historisch bewustzijn

Jasper Delbecke

\section{(2) OpenEdition}

1 Journals

Édition électronique

URL : https://journals.openedition.org/temoigner/5799

DOI : $10.4000 /$ temoigner.5799

ISSN : 2506-6390

Éditeur :

Éditions du Centre d'études et de documentation Mémoire d'Auschwitz, Éditions Kimé

Édition imprimée

Date de publication : 2 avril 2017

Pagination : 134-142

ISBN : 978-2-930953-00-7

ISSN : 2031-4183

Référence électronique

Jasper Delbecke, «Consuming the Holocaust», Témoigner. Entre histoire et mémoire [Online], 124 | 2017,

Online op 30 novembre 2021, geraadpleegd op 01 décembre 2021. URL: http://

journals.openedition.org/temoigner/5799; DOl: https://doi.org/10.4000/temoigner.5799 


\section{Consuming the Holocaust}

\section{Over Sergei Loznitsa's Austerlitz: een subtiel manifest voor een hernieuwd historisch bewustzijn}

Het blijft een onomstotelijke wet van de geschiedenis dat
zij juist tijdgenoten verbiedt de grote bewegingen die hun zij juist tijdgenoten verbiedt de grote bewegingen die h
tijd bepalen al in hun vroegste stadium te herkennen.

(Stefan Zweig, in De Wereld van Gisteren) renlang stelde de Oekraïense film- en documentairemaker Sergei Loznitsa zijn camera op in de concentratiekampen van Sachsenhausen en Dachau. Loznitsa's jongste documentaire Austerlitz (2016) is het ontluisterende resultaat van vele uren opnamemateriaal die de dubbelzinnigheid van het populaire geschiedenistoerisme bloot legt. Zeventig jaar na de gruwel hebben de verschrikkingen van toen plaats geruimd voor Pokémon Go-jagers, hordes slenterende scholieren en cola-slurpende toeristen.

Austerlitz is prachtige meditatieve cinema die scherpe vragen stelt over de rol en de betekenis die we vandaag toedichten aan onze recente Europese geschiedenis. Het is een documentaire die vraagtekens plaats bij de commercialisering en commodificatie van de Holocaust. Deze thema's die Loznitsa in Austerlitz aansnijdt vormen ook de kern van deze bijdrage. Hoe zorgen we ervoor dat de plekken waar de donkerste bladzijden van de menselijke geschiedenis zijn geschreven geen halte worden op een lijst van must sees of must visits? Hoe zorgen we ervoor dat deze plek en de herinnering aan de Holocaust in zijn totaliteit blijft bestaan?

$$
\text { 'COOL STORY, BRO!' }
$$

Austerlitz laat zich lezen als een aaneenschakeling van tableaux vivants binnen en buiten de kampen. Door het oog van de camera observeert de kijker de bezoekers van het concentratiekamp en registreert hun gedrag. Loznitsa fixeert onze blik door de camera niet te bewegen of in te zoomen. Bijna onopgemerkt staat de camera er opgesteld. Wat we te zien krijgen, is niet Sachsenhausen en Dachau maar hun bezoekers. Net zoals in zijn eerdere werk - zoals de documentaire Maidan (2014) of de film In The Fog (2012) - wendt Loznita zijn camera af van de plek waar de dramatische gebeurtenissen zich afspelen en focust op wat errond gebeurt. Hij toont hoe er gekeken wordt en hoe het menselijke lichaam zich verhoudt tot het object warmaar het kijkt. object wamne gebeurtenissen op en rond was gericht op de enorme mensenzee die apathisch de toespraken aanhoort van de Oekraïense politici, op de constante gevechten tussen betogers en de ordediensten. Niet de euforie maar de scepsis na een zoveelste bevlogen politieke speech staat van de gezichten af te lezen. Bij In The Fog (2012), waar het verhaal wordt verteld van opstandige partizanen in het door de nazis bezette Polen, gebruikt Loznitsa dezelfde strategie. De openingsscène van die film brengt de geterroriseerde dorpelingen in beeld die lijdzaam de ophanging aanschouwen van drie mannen uit hun dorp, de blikken afgewend van de lichamen die na een korte doodsstrijd levenloos heen en weer slingeren.

Diezelfde vormelijke keuzes maakt Loznitsa opnieuw in Austerlitz en puurt ze uit tot een eigen vormentaal waardoor de filmshots een grote graad van abstractie krijgen. Voor de kijker is het niet altijd duidelijk waar we ons bevinden. De bewust gekozen vorm- en beeldtaal doet denken aan die van de Duitse fotograaf Thomas Struth. Struth bracht de bezoekers van grote musea als het Louvre, Pergamonmuseum of British Museum op gelijkaardige wijze in beeld. De klemtoon van de beelden komt te liggen op de manier waarop we kijken en bekeken worden. In tegenstelling tot Struth weten we bij Loznitsa niet wat het object van het kijken is. De focus lijkt eerder de afwezigheid te zijn, en het menselijke gedrag tijdens het kijken.

Austerlitz begint aan de metalen poorten van Sachsenhausen waarop de nazileuze Arbeit Macht Freiprijkt Hordes toeristen, in korte broek en geladen met ruszakken die uitpuilen van de frisdrank en versnaperingen, trekken Sachenhausen binnen.

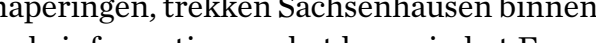
Verslingerd a vans, Engels, Koreaans of Turks influistert. Gretig foto's nemend van de plek waar elke dag duizenden mensen de gruwel moesten doorstaan. Loznitsa manipuleert de werkelijkheid niet die hij filmt. De enige ingreep in de realiteit is zijn aanwezigheid. We zijn getuige van wat er met het menselijk lichaam gebeurt wanneer het rondwandelt in Sachsenhausen. Nooit krijgen we te weten waar de bezoekers precies naar kijken. We zien hen alleen gefascineerd alles observeren; op andere momenten zien we hun aandacht langzaam wegebben. Een puber die wezenloos aan de ingang van Sachsenhausen ronddwaalt in een T-shirt waarop 'Cool Story, Bro!' staat geblokletterd, geeft op subtiele wijze mee wat de rest van Loznita's Austerlitz zal brengen.

Austerlitz is een serene documentaire waarin enkel het beeld spreekt en waar op een fijnzinnige manier wordt getoond hoe een concentratiekamp is geëvolueerd naar een plek waar naar hartenlust wordt gekuierd alsof het een winkelstraat is. 
Scènes waarin Loznitsa zijn lens vastzet op de deuren van verschillende gebouwen van het kamp zijn daar een goede illustratie van. De massa bezoekers schuift in rijen aan om binnen te mogen. Deuren gaan razendsnel open en toe, bezoekers lopen even snel binnen en buiten als in een Primark of McDonald's. De traagheid waarmee Loznitsa alles in beeld brengt en de shots laat afwisselen, staat in schril contrast met de snelheid waarmee de bezoekers het kamp doorkruisen. Volgens filmcriticus en -theoreticus Bill Nichols vormt deze opgelegde traagheid van observeren - door Loznitsa op de spits gedreven - net de kracht van wat hij definieert veren - door Lom als de observational mode van documentaire cinema. De drastische breuk met een narratief en een dramatische lijn stelt Loznitsa in staat om ook poëtische kwaliteiten aan zijn filmisch exposé te verlenen. Filmpionier John Grierson stelde al in de jaren dertig dat het documentaire genre het potentieel in zich draagt om de realiteit op een creatieve manier te behandelen en inhoudelijke vragen te laten samengaan met vormelijke experimenten. Met Austerlitz bewijst Loznitsa dat een bepaalde vormkeuze een extra bijdrage levert aan de manier waarop de realiteit wordt geregistreerd en gerepresenteerd.

Het is de traagheid van filmen die maakt dat het verleden van Sachsenhausen en Dachau op een subtiele manier resoneert in het heden. Zeventig jaar geleden stroomdenhierook duizenden mensen toe, alleen kwamenze er zelden levenden wel stroor (a) slaapvertrekken binnen te mogen, niet om de ontbering te ontvluchten en een slaapplek te vinden maar om deze macabere plekken vast te leggen met hun camera's en smartphones. Austerlitz bulkt van zulke 'flitsen uit het verleden'. Op een gegeven moment stel Loznitsa de camera op voor een groepje toeristen dat onbezorgd zijn lunch zit te nuttigen. Een jongeman veert recht en wil een vlieg van zijn broodje wegslaan. Een bevreemdend schouwspel dat een scherp contrast vormt met de beelden die we kennen van uitgemergelde kampgevangenen of van slachtoffers van de voedselcrisissen in Afrika, en er dus op paradoxale manier naar verwijst. Op het einde van de filmscène deelt de reisgids haor groep mee dat ze best van hun pauze sebruik maken want'dit zal het laatste moment zijn dat ze iets kunnen eten' Opnieuw een tafereel dat een zal het laatste moment zijn dat ze iets kunnen eten'. Opnieuw een tafereel dat een

\section{W.G. SEBALD ACHTERNA: HOE INDIVIDUEEL EN COLLECTIEF HERDENKEN?}

De titel Austerlitz alludeert op de gelijknamige roman uit 2001 van de Duitse schrijver W.G. Sebald. Loznitsa ziet zijn documentaire als een adaptatie van, en variatie op het boek. Sebalds Austerlitz vertelt het verhaal van een historicus die in de wachtzaal van het Antwerpse stationsbuffet de zwaarmoedige Jacques Austerlitz ontmoet. Tijdens hun gesprekken onthult Austerlitz stap voor stap zijn levensverhaal: een wanhopige zoektocht naar identiteit van een eenzame man die als kind werd beroofd van zijn va werd litzeer litz weer in contact ook een uitstekende oefening voor de geschiedkundige. De historicus is volgens hem als een voddenverzamelaar - Lumpensammler - die de wereld en de stad in trekt om daar schijnbaar onbenullige en betekenisloze objecten te verzamelen. Door middel van montage en puzzelwerklegthijvervolon gens de bouwstenen van het verleden samen enlichten er nieuwe verklaringen en betekenissen op. Historicus Pierre Nora besloot met zijn Lieux de mémoire (1984-1992) dat de mens meer waarde hecht aan persoonlijke ervaringen en herinneringen dan aan grote historische gebeurtenissen of omwentelingen. Die gedachte vormt ook het uitgangspunt van Loznitsa's Austerlitz. De filmmaker groeide zelf p in eem fomilie diez op in een famille die zwaar heeft geledenonder Vele van zijn familieleden zijn spoorloos verdwenen

Loznitsa's poging om kennis te vergaren over zijn eigen geschiedenis en die van anderen beantwoordt aan een verlangen dat de afgelopen

jaren sterk is gegroeid in onze westerse samenleving. Geschiedenis was nog nooit zo aanwezig als vandaag 'Het verleden' 'het reheugen' 'berinneren' en 'trauma' zijn them's die binne 'Het vema' blijft het verleden ons vandaag fascineren, achtervolgen, inspireren en om ons rondspoken. Francis Fukuyama sloeg de bal mis in zijn The End of History and the Last Man (1992) toen hij poneerde dat het liberale gedachtegoed de rol van geschiedenis zou overnemen. Het tegenoverstelde lijkt waar.

In zijn boek Present Pasts: Urban Palimpsests and the Politics of Memory (2003) spreekt Andreas Huyssen van een 'hypertrophy of memory' vandaag de dag. Volgens de auteur is onze obsessie met herinnering een indicatie van de enorme verschuivingen, schaalvergrotingen en tempowissels die de manier kenmerken waarop we denken over (en leven in) tijd en ruimte. Terwijl in de huidige neoliberale ideologie onze toekor (en lin het teken stat van voortduje onze toek Volgens 
leden, met een doorgedreven 'musealisering' tot gevolg. 'Het verleden verkoopt nu eenmaal beter dan de toekomst', stelt de auteur, maar hij waarschuwt ook dat 'het verleden [...] ons nooit [kan] geven waar de toekomst niet in slaagt'. Het is de vreemde temporele spreidstand waarvan we vandaag getuige zijn.

In The Future of Nostalgia (2001) komt Svetlana Boym tot een gelijkaardige conclusie. Zij definieert onze omgang met het verleden als 'nostalgisch': het is niet zozeer een verlangen naar het verleden zoals het is geweest, maar een verlangen nar een verledenzols hethadkunnen zijn. Parllel naar eevis Reynebeau in zijn essay Nostalgie, eenemotiemet toekomst (2016) dat nostalgie voora is ingegeven door een vervreemding van de mens met het heden. Zowel Huyssen, Boym als Reynebeau stellenvast dat de gemaakte beloftes van de nieuwe neoliberale wereldorde de afgelopen drie decennia niet voor iedereen een realiteit zijn geworden. De ontgoochelde mens gaat daardoor weer verlangen naar een verleden waar er nog 'zekerheden' waren, en past de denkkaders uit dat verleden toe op de toekomst.

Huyssen en Boym schetsen hoe dat mechanisme werkt op het niveau van het individueel en collectief herinneren en herdenken. Reynebeau gaat een stap verder en stelt dat nostalgie het ideale politieke wapen is geworden in een wereld waarin de globalisering zijn grenzen begint te kennen. (Res)sentimenten die politici als Nigel Farage of Donald Trump handig wisten te bespelen. Deanalyses van Huysen, Boym Huyssen, Boym en Reynebeau wijzen op de gevaren en valkuilen van zulke eenzijdige en dogmatische
omgang met het verleden. In zijn Regimes of

In zijn Regimes of Historicity. Presentism and Experiences of Time (2015) stelt Hartog dat elke gemeenschap haar eigen temporele orde of 'historiciteitsregime' handhaaft die het raamwerk bepaalt waarbinnen de kennis, ervaring en representatie van verleden, heden en toekomst vorm krijgen. Filosoof Frederik Le Roy $(2012,8)$ wijst op het canoniserende effect van elk historiciteitsregime: sommige historische narratieven worden bekrachtigd, andere worden uitgesloten en dreigen daardoor tussen de plooien van de geschiedenis te verdwijnen. Huyssen, Boym en Reynebeau wijzen in hun analyses op de blinde vlekken van ons huidig historiciteitsregime en

\section{DE TERUGKEER NAAR DE DINGEN}

Een poging om een nieuw historiciteitsregime te initiëren zien we bij historicus Eelco Runia, die de notie van presence naar voren schuift als alternatief voor een puur epistemologische en hermeneutische reductie van de geschiedenis (Runia 2006). In plaats van de ontmoeting met het verleden te herleiden tot de kennis van feiten, data en begrippen, bepleit de auteur een onbemiddelde aanwezigheid van het verleden in het heden, waardoor we rechtstreeks in contact staan met een historische werkelijkheid en die ten volle ervaren In Runia's presence-begrip weerklinken Johon Huizing's 'historischer die de historicus gewaarwordt wanneer ongekende elementen uit het verleden zich aandienen (Tollebeek \& Verschaffel 1992; Ankersmit 1993). Het gaat om een rechtstreekse ervaring van het verleden, los van context en discours, ontdaan van taal en interpretatiekaders. Ankersmits 'sublieme historische ervaring' is vergelijkbaar en gaat gepaard met een besef dat het verleden zich heeft losgerukt van het heden en onherroepelijk verloren is gegaan (Ankersmit 2007). Historica Ewa Domanska zit op dezelfde golflengte en pleit voor een 'terugkeer naar de dingen' (Domanska 2006). Deze nieuwe geschiedfilosofische tendens kent heel wat parallellen met het discours naneen nieuwe generatie denkers binnentefilos discours als Bruno Latour, Graham Harman of Quentin Meillassoux ontwikkelen een filosofisch project waarin objecten als objecten worden gedacht. Daarin hebben objecten ook een bestaan, onafhankelijk van het diepgewortelde menselijk perspectief. Deze nieuwe filosofische stroming - het speculatief realisme - wil zich afscheuren van een lange traditie in de westerse filosofie die objecten enkel in relatie tot mensen kon denken en ze niet zag als autonome dingen. In een wereld waarin de mens de eindigheid van materie op aarde vaak aan den lijve ondervindt en waarin machines en digitale structuren onze werkelijkheid vormen, is een hernieuwd respect voor objecten meer dan ooit noodzakelijk.

Concreet betekent dat voor de herinneringspraktijk: op zoek gaan naar de materiële sporen van het verleden in het heden, in een poging om de geschiedenis te riêle sporen van het veleden in het hedn, in herdenken in een context die wars is van semiotiek en discours. De nadruk op de 'directe ervaring zien we de laatste jaren terugkeren in vele historische musea en sites. Het onbemiddelde contact met het 'authentieke' verleden moet kennis en inzicht opleveren bij de bezoeker. In België waren we daar getuige van naar aanleiding van de honderdjarige verjaardag van de Eerste Wereldoorlog. Evocaties, re-enactments en bezoeken aan de loopgraven moesten de bezoekers laten 'ervaren' en 'voelen' hoe het leven aan het front was. Deze reeks van herdenkingen ging onvermijdelijk gepaard met een grote commercialisering van de verjaardag: de Eerste Wereldoorlog werd gecommodificeerd in functie van het oorlogstoerisme. De populariteit van een kampbezoek in Auschwitz of Sachsenhausen kunnen we plaatsen binnen deze tendens.

\section{COLLECTIEF HERDENKEN EN MASSATOERISME: EEN MOEILIJK EVENWICHT}

Hoe zorgen we ervoor dat dit 'onbemiddelde en authentieke contact' met het verleden voldoende diepgang en gelaagdheid kent? Dat het historische bewustzijn het blijft halen van de shopping-logica? Het zijn vragen die Sergei Loznitsa zich stelde na een bezoek aan Buchenwald. Toen hij in het crematorium stond van het kamp, omringd door medebezoekers die duchtig foto's namen, voelde Loznitsa zich een toerist. Hij was beland in een bevreemdende situatie waarin bezoekers consu-

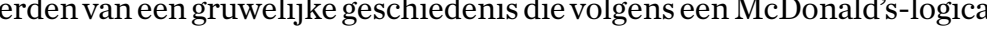
genuttigd kon worden: à la carte, naar eigen smaak en voorkeur.

Austerlitz bevat twee scenes waarin, op zijn zachtst uitgedrukt, twee bedenkelijke handelingen te zien zijn. In een eerste scène zien we een groep die een aparte afdeling 
van een van de kampen bezoekt waarin mensen werden opgesloten in cellen met dichtgemetselde ramen en hardhandig werden ondervraagd door de Gestapo. Degids vertelt hoe gevangenen die weigerden te spreken, tot de dood werden gemarteld aan drie centraal opgestelde schandpalen. Hun geschreeuw was te horen in alle cellen van het kamp. Wanneer de groep daarna verder wandelt, stapt een man naar een van de drie palen en poseert als een geboeide gevangene voor de foto. Wat vertel je als je die foto achteraf aan vrienden toont?

Het meest stuitende beeld bewaart Loznitsa voor het einde van zijn documentaire. Austerlitz begint zoals hij eindigt, aan de toegangspoort van Sachsenhausen We zien de scholengroepen naar buiten slenteren, blij huiswaarts te keren na een lange dag. Uit de mensenzee houden drie personen halt voor de toegangspoort. Een gezin: moeder, vader en dochter, de dochter met selfiestick in de hand. Het 'uitstapje' naar Sachsenhausen wordt zo afgesloten met een selfie van het drietal onder de slogan Arbeit Macht Frei. Loznitsa gebruikt de term 'kafkaiaans' om zijn ervaring in Buchenwald te omschrijven, maar bij het zien van de slotscène kunnen we daar gerust 'absurd' aan toevoegen. De selfie is de ideale manier om in een individualistische maatschappij het ego te presenteren aan de buitenwereld en te tonen 'dat je erbij was'. De eigen persoon staat centraal, de rest van het beeld is opvulling Mar wat vertelt een beeld over je ego als de woorden Arbeit Macht Frei opvulling boven je hoofd opd of Instagram verschijnt? Hoe reageert een familielid van iemand die slachtoffe was van de Holocaust wanneer die de foto van het gezin te zien krijgt? Los van het feit dat de Arbeit Macht Frei-selfie bewijst dat we de ingebakken reflexen niet van ons kunnen afwerpen, is hij misschien wel illustratief voor het onvermogen om de historische betekenis van de gebeurtenissen te vatten.

Austerlitz confronteert de kijker met een dilemma: hoe zorgen we ervoor dat een bezoek aan Sachsenhausen of Dachau voor altijd een verpletterende indruk nalaat en niet louter als een toeristisch 'uitstapje' wordt beschouwd? Hoe blijven we hier als gemeenschap uit leren zonder het 'normaal' te gaan vinden? Filosofen Alain Badiou (2007a; 2007b) en Slavoj Žižek (2014) wijzen op het gevar van 'normalisering' dat e malisering date zwaard van Damocles boven het hoofd hangt. Normalisering verlaagt onze ethisch standaarden, laat een gedachteloze en lethargische omgang met ons verleden toe en werkt het ontbreken van een kritisch bevraging in de hand met betrekking to de wijze waarop onze geschiedenis wordt gerepresenteerd. Om het polemisch te stellen in Hannah Arendts woorden: zijn het net niet de 'pure gedachteloosheid' en het 'gebrek aan werkelijkheidszin in een mens die meer onheil kunnen aanrichten dan alle boze driften die het mensenhart eigen zijn tezamen?' Natuurlijk kunnen we de bezoekers van de concentratiekampen niet op één lijn plaatsen met de nazi's. Wel moeten we erblijvend op wijzen dat, zoals Arendt stelde het kritiek-engedachteloos in het leven staan net heeft kunnen leiden tot dergelijke gebeurtenissen.

Het historische besef wordt in de kampen bovendien vaak bemoeilijkt door de afwezigheid van de gruwel. De gapende afstand tussen de gruwel van toen en de plek vandaag wordt steeds groter. Dat bewijst de scène in Austerlitz waarin de camera staat opgesteld aan het eind van een lange gang, ergens in een van de kampen. We zien bezoekers door de gang wandelen en af en toe even halt houden om via een klein luikje een kamer binnen te kijken. Plots duikt een jong meisje op dat in een rotvaart van deur naar deur rent, zich omhoog hijst en naar binnen gluurt. Ze is op zoek naar een teken van leven, iets dat doet denken aan de menselijke aanwezigheid die er ooit was. Loznitsa toont verder een leeg kamp in een desolate vlakte, met barakken en ovens die slechts vag doen denken aan wat er vroeger heeft plats gevonden. en ov dienten. Infoborden atsen op de onmoget kheid on de uitroilng van mensen op industriele schaal rationeel en narratief te benaderen. De enige resten van het verleden die we in Austerlitz te zien krijgen, zijn trouwens die van de nazi's. Van de Joden is er geen spoor meer. Dertig jaar na Claude Lanzmanns Shoah (1985), waarin onder andere de problematische houding van de getuigen van die tijd wordt aangekaart, toont Sergei Loznitsa's Austerlitz de gewrongen verhouding van de hedendaagse getuigen (de bezoekers van de kampen) en het verleden dat zij proberen te herdenken. We zien hier de grenzen en valkuilen die grootschalige herdenkingen met zich mee brengen. Waar Lanzmann met Shoah (1985) toonde Lan het nazi-apparat er in gesta hoe het nazi-appater in geslaagd was om burgers machine, zo toont Loznitsu's Austerlitz hoe burgers opnieuw kritiekloos worden meegesleurd in de commerciële machinerie die aan basis ligt van dit soort oorlogstoerisme. De vakantiekiekjes hebben het gehaald van het historische bewustzijn. Daarom is het meer dan ooit nodig datde gewrongen relatie van de mens met $z$ jinven relatievande voorzien wint geschiedschrijuing die niet zwart-wit is maar bulkt van de grijswaarden. Kunst kan die grijswaarden tonen of minstens de nood eraan.

Theodor W. Adorno opperde in 1949 dat kunst maken na Auschwitz onmogelijk was. In zijn essay Figures of History (2014) dient de Franse filosoof Jacques Rancière Adornovan antwoord en keert diens uitspran om. Volgens Rancière is kust het enige dat mogelijk is na Auchwitz,
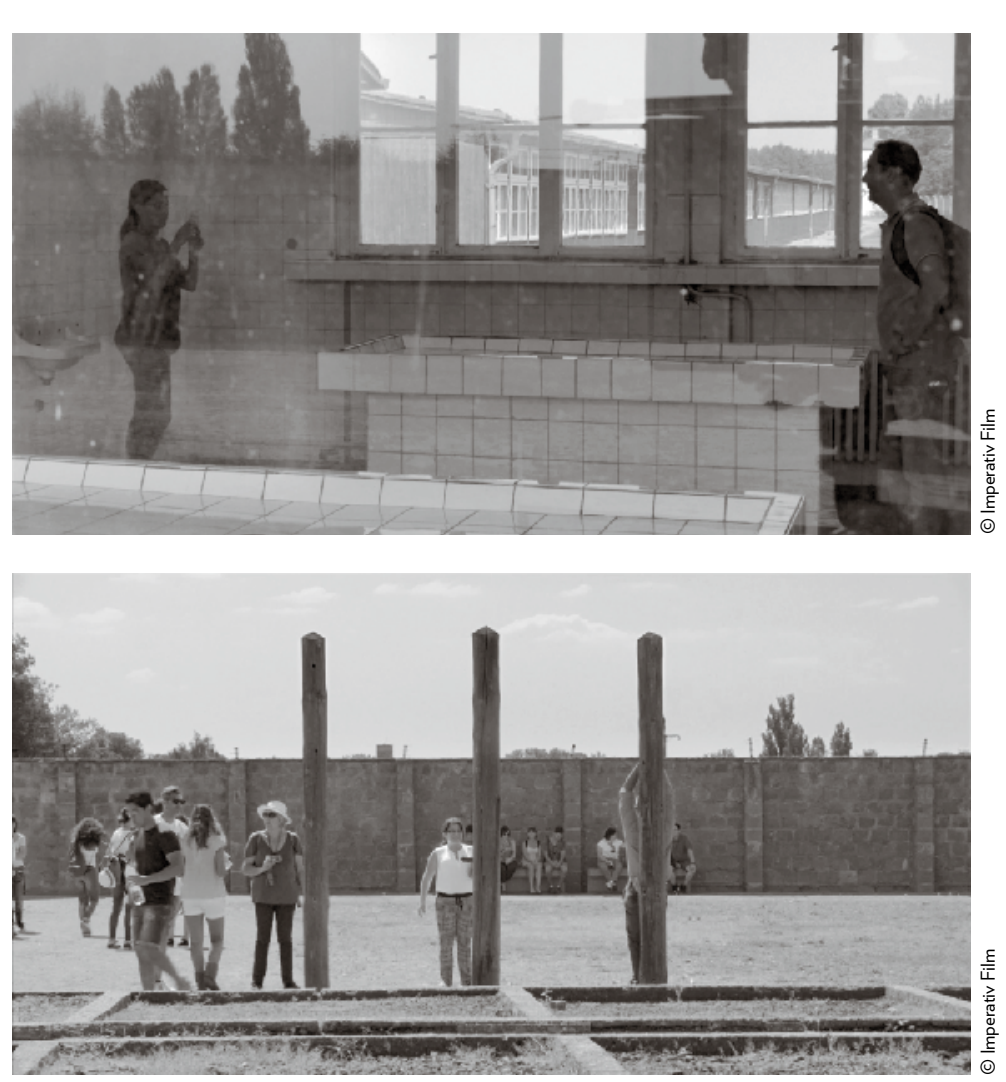
om de gruwel te tonen. Kunst toont de aanwezigheid van het 'afwezige'. Haar taak bestaat erin om via beelden en woorden het onzichtbare te tonen en het onmenselijke waarneembaar te maken. Enkel via deze weg kunnen we volgens Rancière de 'Vernichtung' vermijden: het reduceren van de Holocaust tot iets futiels, de vernietiging van de vernietiging, het verdwijnen van de sporen. De opdracht voor kunst én geschiedenis bestaat er vandaag in om het proces van vergetelheid, verdwijnen en amnesie te tonen en te bekritiseren, en zo te vermijden dat de nazi's uiteindelijk toch hun doel bereiken: het 'wegwissen' van de Joden. Sachsenhausen of Dachau hebben hun pedagogisch-geschiedkundige functie niet verloren door het massatoerisme, maar Loznita's Austerlitz wijst wel op de grenzen en valkuilen van het soort relatie dat we daar met het verleden aangaan.

\section{BIBLIOGRAFIE}

- Giorgio Agamben, Remnants of Auschwitz. The Witness and the Archive [1999], vertaald uit het Italiaans door Daniel Heller-Roazen, New York: Zone Books, 2002.

- Frank R. Ankersmit, De sublieme historische ervaring, Groningen: Historische Uitgeverij, 2007.

----, De historische ervaring, Groningen: Historische Uitgeverij, 1993

- Hannah Arendt, Eichmann in Jeruzalem. De Banaliteit van het Kwaad [1963], Amsterdam: Uitgeverij Atlas Contact, 2014.

- Alain Badiou, Being and Event [1988], vertaald uit het Frans door Oliver Feltham, London \& New York: Bloomsburry, 2007a.

- ---, The Century, vertaald uit het Frans door Alberto Toscano, Cambridge: Polity Press, 2007b.

- Svetlana Boym, Another Freedom. The Alternative History of and Idea, Chicago \& Londen: University of Chicago Press, 2010.

- ---, The Future of Nostalgia, New York: Basic Books, 2001.

- Eva Domanska, 'The Material Presence of the Past', History and Theory 45, 2006, 337-348.

- Francis Fukuyama, The End of History and the Last Man, Free Press, 1992.

- François Hartog, Regimes of Historicity. Presentism and Experiences of Time [2003], vertaald uit het Frans door Saskia Brown, New York: Columbia University Press, 2015.

- Graham Harman, Towards Speculative Realism: Essays and Lectures. Winchester: Zero Books, 2010.

- Andreas Huyssen, Present Pasts. Urban Palimpsests and the Politics of Memory, Stanford: Stanford University Press, 2003.

- Claude Lanzman, Shoah (film), 1985.

- Bruno Latour, We have Never Been Modern, vertaald uit het Frans door Catherine Porter, New York: Harvester Wheatsheaf, 1993.
- Frederik Le Roy, Verknoopte tijd, verfrommelde geschiedenis. een theaterwetenschappelijk en geschiedfilosofisch onderzoek naar theater en performance als politiek van de herinnering in het modern en presentistisch historiciteitsregime, doctoraatsproefschrift Universiteit Gent, Faculteit Letteren \& Wijsbegeerte, 2012.

- Quentin Meillassoux, Na de eindigheid. essay over de noodzakelijkheid van contingentie [2006], vertaald uit het Frans door Joost Beerten, Uitgeverij Leesmagazijn, 2016.

- Bill Nichols, Introduction to Documentary, Indiana University Press, 2010.

- Pierre Nora, Les Lieux de mémoire, Parijs: Gallimard, 1984-1992.

- Jacques Rancière, Figures of History [2012], vertaald uit het Frans door Julie Rose, Cambridge \& Londen: Polity Press, 2014.

- ---, The Future of the Image [2007], vertaald uit het Frans door Gregory Elliott, Londen \& New York: Verso Books, 2009.

- Nicolas Rapold, 'Sergei Loznitsa's Movie “Austerlitz” Observes Tourists in Concentration Camps', New York Times, 31 augustus 2016, http://www.nytimes.com/2016/08/31/arts/international/sergei-loznitsamovie-austerlitz-tourists-concentration-camps.html?_r=0 (geraadpleegd 6 december 2016).

- Marc Reynebeau, 'Nostalgie, een emotie met toekomst', De Standaard, 5 november 2016.

- Eelco Runia, 'Presence', History and Theory 45, 2006, 1-29.

-W.G. Sebald, Austerlitz, vertaald uit het Duits door Anthea Bell, New York: Random House, 2001.

- Jo Tollebeek \& Bart Verschaffel, De vreugden van Houssaye. Apologie van de historische interesse, Amsterdam: Wereldbibliotheek, 1992.

- Slavoj Žižek, Event. Philosophy in Transit, Londen \& New York: Penguin Books, 2014. 